\title{
Amplification of apoptosis through sequential caspase cleavage of the MET tyrosine kinase receptor
}

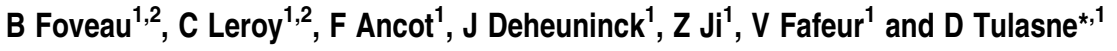

Activation of the MET tyrosine kinase receptor by hepatocyte growth factor/scatter factor is classically associated with cell survival. Nonetheless, stress stimuli can lead to a caspase-dependent cleavage of MET within its juxtamembrane region, which generate a proapoptotic $40 \mathrm{kDa}$ fragment (p40 MET). We report here that p40 MET is in fact generated through an additional caspase cleavage of MET within its extreme C-terminal region, which removes only few amino acids. We evidenced a hierarchical organization of these cleavages, with the C-terminal cleavage favoring the juxtamembrane one. As a functional consequence, the removal of the last amino acids of p40 MET increases its apoptotic capacity. Finally, cells expressing a MET receptor mutated at the C-terminal caspase site are unable to generate p40 MET and are resistant to apoptosis, indicating that generation of p40 MET amplifies apoptosis. These results revealed a two-step caspase cleavage of MET resulting in the reshaping of this survival receptor to a proapoptotic factor.

Cell Death and Differentiation (2007) 14, 752-764. doi:10.1038/sj.cdd.4402080; published online 22 December 2006

The hepatocyte growth factor/scatter factor (HGF/SF) is a pleiotropic growth factor that acts through the MET tyrosine kinase receptor in a variety of cell types. ${ }^{1-3}$ Upon HGF/SF binding, the MET receptor is dimerized and its tyrosine kinase activity stimulated with autophosphorylation of the receptor. ${ }^{4}$ Two phospho-tyrosine residues located in the C-terminal tail of the receptor have been identified as multifunctional docking site, able to interact with several cytoplasmic signal transducers. ${ }^{5,6}$ Recruitment through these tyrosine residues play a crucial role in mediating biological responses to HGF/SF. ${ }^{7}$ In contrast to the positive signaling triggered by the C-terminal tail, the juxtamembrane region is endowed with several negative regulatory sites, which are involved in recycling and/or degradation of the receptor. ${ }^{8-12}$

The ligand-activated MET stimulates proliferation, scattering, invasion and morphogenesis of epithelial cells, acts as an angiogenic factor and has chemoattractant and neurotrophic activities. HGF/SF is also a survival factor, which protects a number of cell types against cell toxicity and apoptosis. ${ }^{13-15}$ Phenotypic analysis of hgf or met null mice have shown that HGF/SF-MET signaling is essential for hepatocyte survival, as these mice display a severe size reduction of the liver and show massive apoptosis. ${ }^{16-18}$

We recently reported that MET is a functional target of caspases. ${ }^{19}$ Indeed, we have shown that stress stimuli induce the caspase cleavage of MET at aspartic residue 1000 within the ESVD motif of the juxtamembrane region of mouse MET. This cleavage generates an intracellular $40 \mathrm{kDa}$ fragment containing the kinase domain. The p40 MET fragment itself causes apoptosis, whereas its kinase dead version is impaired in proapoptotic activity.

Activation of caspases during apoptosis results in proteolytic cleavage of a variety of substrates, which may directly contribute to the apoptotic process. In most cases, the cleavage inactivates the targeted substrate. ${ }^{20}$ For instance, inhibitor of caspase-activated DNase (ICAD) is inactivated by caspase- 3 cleavage, which allows activation of the caspase-activated DNase (CAD) and DNA fragmentation characteristic of apoptosis. ${ }^{21,22}$ Nonetheless, in some cases, caspase cleavage was found to activate the targeted substrate. For instance, cleavage of the serine/threonine kinase Rho-associated kinase 1 increases its kinase activity, leading to phosphorylation of the myosin light chain and membrane blebbing characteristic of apoptosis. ${ }^{23,24}$ The caspase cleavage in the juxtamembrane domain of MET leads to the generation of a proapoptotic factor, whereas the ligand-activated receptor induces survival. Thus, in the case of MET, caspase cleavage induces an original conversion from a survival receptor to a proapoptotic factor. The mechanisms of this conversion through caspase cleavage were unknown. We show here that in addition to the juxtamembrane cleavage, the MET tyrosine kinase is cleaved by caspases within its $\mathrm{C}$-terminal extremity. By characterizing this cleavage site, we found that this additional cleavage is essential for triggering proapoptotic activity of the p40 MET fragment.

\footnotetext{
${ }^{1}$ CNRS UMR 8161, Institut de Biologie de Lille, CNRS-Institut Pasteur de Lille-Université de Lille 1-Université de Lille 2, Lille cedex, France

${ }^{*}$ Corresponding author: D Tulasne, CNRS UMR 8161, Institut de Biologie de Lille, Institut Pasteur de Lille, BP447, 59021 Lille, France. Tel: + 33320871091 Fax: + 333208711 11; E-mail: david.tulasne@ibl.fr

${ }^{2}$ These authors contributed equally to this work.

Keywords: c-MET; tyrosine kinase receptor; hepatocyte growth factor; apoptosis; caspase

Abbreviations: HGF/SF, hepatocyte growth factor/scatter factor; NGF, nerve growth factor; TNF, tumor necrosis factor; CAD, caspase-activated DNase; ICAD, inhibitor of caspase-activated DNase; ROCK1, Rho-associated kinase 1; MAPK, mitogen-activated protein kinase; ERK, extracellular-regulated kinase; RasGAP, Ras GTPase-activating protein; CBL, Casitas b-lineage lymphoma; PDGF $\beta$-R, platelet-derived growth factor beta receptor; zVAD-FMK, Z-Val-Ala-Asp (OMe)-fluoromethyl ketone; MDCK, Madin-Darby Canine Kidney; HEK293, human embryonic renal epithelial cell 293; HeLa cells, human epithelial cells from cervical carcinoma; FCS, fetal calf serum; SDS-PAGE, sodium dodecyl sulfate-polyacrylamide gel electrophoresis

Received 15.2.06; revised 27.10.06; accepted 10.11.06; Edited by SJ Martin; published online 22.12.06
} 


\section{Results}

Stress induces both juxtamembrane and C-terminal cleavages of MET. TRK-MET receptors are known to mediate MET-specific signals in epithelial cells in response to nerve growth factor (NGF). ${ }^{25,26}$ These chimeras consist of the extracellular portion of TRK-A coupled to the trans- membrane and intracellular domains of MET. In order to facilitate its detection, we tagged TRK-MET with C-terminal V5 epitope.

The TRK-MET V5 expression plasmid was stably transfected in Madin-Darby Canine Kidney (MDCK) epithelial cells. The chimeric receptor was detected at the expected size using an anti-murine MET antibody (Figure 1a and b, left a

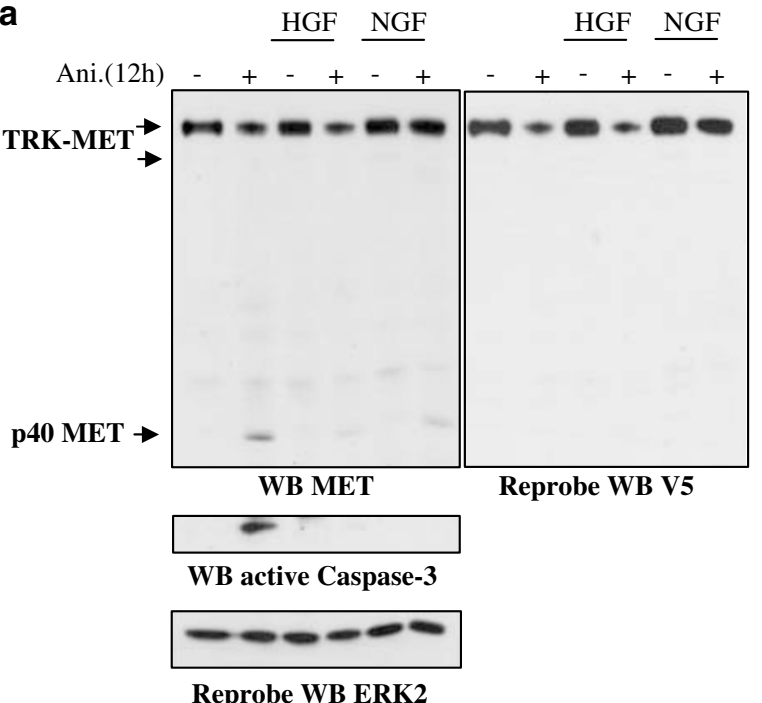

Reprobe WB ERK2

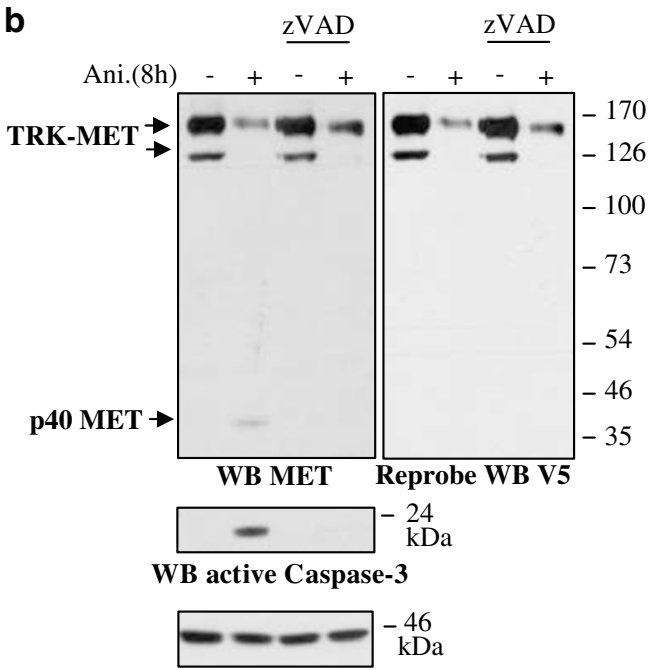

Reprobe WB ERK2

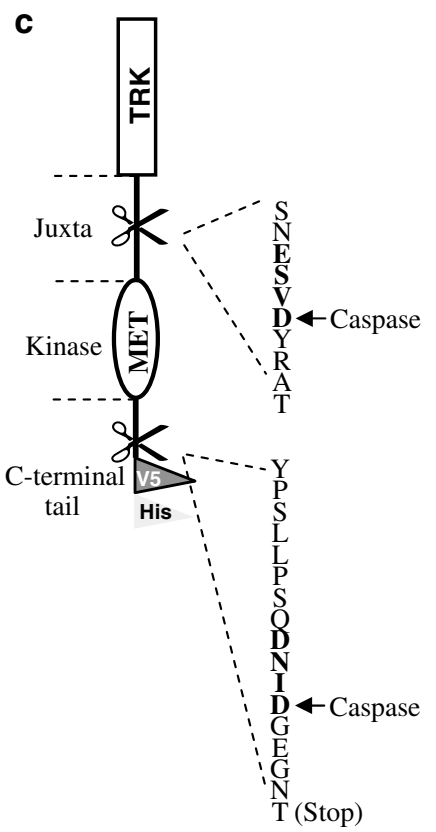

d

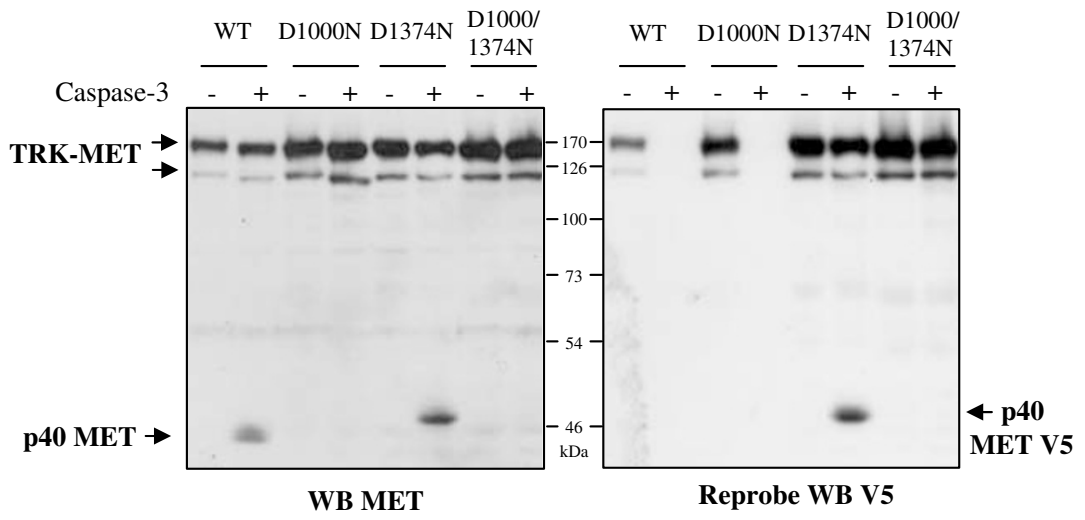

Figure 1 Tagged version of TRK-MET reveals C-terminal caspase cleavage. (a) MDCK epithelial cells, stably transfected with the TRK-MET V5 WT chimera, were pretreated or not for $1 \mathrm{~h}$ with HGF/SF $(10 \mathrm{ng} / \mathrm{ml})$ or NGF $(100 \mathrm{ng} / \mathrm{ml})$ and then treated or not for $12 \mathrm{~h}$ with anisomycin (Ani., $50 \mu \mathrm{M})$. (b) MDCK epithelial cells, stably transfected with the TRK-MET V5 WT chimera, were treated for $8 \mathrm{~h}$ with anisomycin (Ani., $50 \mu \mathrm{M}$ ), in the presence or absence of ZVAD-FMK (zVAD, $20 \mu \mathrm{M})$. (a, b) For each condition, the same amount of proteins was resolved by $10 \%$ SDS-PAGE and analyzed by Western-blotting using an antibody directed against mouse MET (top panel). The membrane was stripped and reprobed sequentially using an anti-V5 antibody (right panel) and an anti-ERK2 antibody to assess comparable loading (lower panel). Lower part of the filter was analyzed by Western blotting using an anti-active caspase-3 antibody (middle panel). Arrows indicate positions of the p150 TRK-MET (fully glycosylated), p125 TRK-MET (partially glycosylated) and p40 MET fragment. (c) Schematic representation of the TRK-MET V5-His receptor with murine sequences of the juxtamembrane caspase site and putative C-terminal caspase site. (d) Cell extracts of MDCK, stably transfected with the TRK-MET V5 WT, D1000N, D1374N, D1000/1374N, were incubated with purified caspase-3. Samples were then resolved by 10\% SDS-PAGE and analyzed by Western blotting using an anti-mouse MET antibody (left panel). The filter was stripped and reprobed using an anti-V5 antibody (right panel). Arrows indicate positions of the p150 TRK-MET, p125 TRK-MET, p40 MET fragment and p40 MET-V5 fragment 
panel). TRK-MET detection was similarly obtained using an anti-V5 antibody (Figure $1 \mathrm{a}$ and $\mathrm{b}$, right panel). Treatment of these cells with the apoptotic inducer anisomycin causes within several hours activation of caspase-3 and generation of p40 MET (Figure 1a).

According to the anti-apoptotic property of the endogenousactivated MET receptor, HGF/SF stimulation induced survival of MDCK cells, accompanied by decrease of caspase-3 activation and p40 MET generation (Figure 1a). Similar effects were obtained with NGF in MDCK cells stably transfected by TRK-MET, confirming the functional activation of the chimera (Figure 1a). In addition, treatment with the pan caspase inhibitor zVAD inhibited both caspase-3 activation and p40 MET generation (Figure 1b).

Although these data were expected, the V5 antibody was not able to detect the generated p40 MET (Figure 1a and b), suggesting that the C-terminal tag was lost by cleavage during apoptosis. This led us to examine further the possible existence of a C-terminal caspase-dependent cleavage of MET.

C-terminal cleavage occurs at aspartic acid 1374. As mouse MET contains a putative caspase site $\left(D I_{1374}\right)$ located five amino acids upstream of the stop codon, we investigated whether a caspase cleavage could occur at this site (Figure 1c). Experiments were performed using MDCK cells stably expressing TRK-MET receptors, in which aspartic acid was replaced or not by asparagine in the juxtamembrane (D1000N) and C-terminal (D1374N) regions (Figure 1c). Cell extracts were incubated with active caspase-3 and the TRK-MET receptors detected using either anti-MET or anti-V5 antibodies. Incubation of TRKMET WT with caspase-3 allowed generation of p40 MET detected with the anti-MET antibody (Figure 1d, left panel). In contrast, p40 MET and full-length MET receptor were not detected using the anti-V5 antibody, demonstrating the Cterminal cleavage (Figure 1d, right panel). As expected, from TRK-MET D1000N expressing cells, p40 MET was not generated, whereas the C-terminal cleavage was still effective. From TRK-MET D1374N, p40 MET was still generated and was detected with the anti-V5 antibody (Figure 1d). The size of the p40 MET fragment generated was slightly increased, in agreement with the presence of the V5 tag. From TRK-MET mutated on both sites, p40 MET generation was abolished and V5 detection of TRK-MET conserved. These results demonstrate that aspartic acid D1374 is required for in vitro C-terminal cleavage by caspase-3. Similarly, mutation $\mathrm{D} 1371 \mathrm{~N}$ resulted in abolition of the C-terminal cleavage, indicating that the DNID sequence is the caspase target motif (data not shown).

Mutation of the C-terminal caspase site prevents juxtamembrane cleavage. We next evaluated the consequence of mutating the C-terminal caspase site on the fate of the MET receptor subjected to cellular stress. MDCK cells were transiently transfected with TRK-MET chimeras, and cell extracts were analyzed by Western blot using either anti-MET or anti-V5 antibody. In cells transfected with TRK-MET WT, p40 MET and the full-length receptor were detected (Figure 2a). In this condition, p40 MET was detected as a doublet with the upper band corresponding to phosphorylated p40 MET. ${ }^{19}$ In cells transfected with TRKMET D1000N, p40 MET was not observed. It is worth noticing that stress induced by transient transfection was sufficient to promote cleavages. Although this was inhibited by caspase inhibitor (Supplementary data, Figure S1), we did not observe caspase-3 activation in transient transfected cells. This stress could however induce weak activation of caspase-3, which could be under the level of detection or activate other caspases. Importantly, in cells transfected with TRK-MET D1374N detection of p40 MET using an anti-MET antibody was strongly decreased in comparison to TRK-MET WT (Figure 2b, left panel, lanes 2 and 4). The reprobe with V5 antibody shows that remaining p40 MET generated by TRK-MET D1374N is still V5 tagged (Figure 2a, right panel, lane 4). Therefore, this result indicates that mutation of the C-terminal caspase site prevents cleavage within the juxtamembrane region.

To investigate further this result, apoptosis was induced in stably transfected MDCK cells, which express comparable levels of TRK-MET. As shown in Figure 2b, following proapoptotic stimuli, p40 MET was generated from TRKMET WT but not from TRK-MET D1000N. Cells expressing TRK-MET with D1000N mutation displayed also lower activation of caspase-3 (Figure $2 b$ ) and lower cell death measured by trypan blue exclusion (Figure 2c). This indicates that cells expressing TRK-MET with D1000N mutation were more resistant to apoptosis. These results are consistent with previous studies showing that the aspartic acid D1000 and the adjacent phosphorylated tyrosine $\mathrm{Y} 1001$ constitute an interaction motif to $\mathrm{CBL}$, which is involved in ubiquitination and degradation of activated MET. ${ }^{27}$ Accordingly, it has been shown that mutation of D1000 or Y1001 impaired MET-CBL interaction and induced constitutive scattering of MDCK cells. $^{10,25,27}$ MDCK cells expressing TRK-MET D1000N display similar constitutive scattering (Supplementary Data,

Figure 2 Mutation of the C-terminal caspase site inhibits juxtamembrane cleavage. (a) MDCK cells were transiently transfected with vectors either empty or expressing TRK-MET V5 WT, D1000N, D1374N and D1000/1374N. The following day, cells were lyzed. For each condition, the same amount of proteins was resolved by $10 \%$ SDSPAGE and analyzed by Western blotting using an antibody directed against mouse MET (left panel). The filter was stripped and reprobed using an anti-V5 antibody (right panel). Arrows indicate positions of TRK-MET V5 and lines indicate positions of p40 MET and p40 MET V5 fragments. (b) MDCK epithelial cells, stably transfected with the TRK-MET V5 WT, D1000N, D1374N, D1000/1374N were treated for $8 \mathrm{~h}$ with anisomycin (Ani., $50 \mu \mathrm{M}$ ). For each condition, the same amount of proteins was resolved by $10 \%$ SDS-PAGE and analyzed by Western-blotting using an anti-mouse MET antibody (top panel). The filter was stripped and reprobed sequentially using an anti-V5 antibody (right panel) and an anti-ERK2 antibody to assess comparable loading (lower panel). Lower part of the filter was analyzed by Western blotting using an anti-active caspase-3 antibody (middle panel). Arrows indicate positions of TRK-MET V5, p40 MET and p40 MET-V5 fragments. (c) Stable MDCK cells were treated for $8 \mathrm{~h}$ with either anisomycin (Ani., $50 \mu \mathrm{M})$ or TNF $\alpha(30 \mathrm{ng} / \mathrm{ml}) /$ cycloheximide (CHX, $10 \mu \mathrm{g} / \mathrm{ml})$. Cells were then stained with Trypan Blue. Percentage of dead cells stained in blue were determined $(n=3$; \pm S.D.) 
Figure S2). Importantly, in cells expressing TRK-MET D1374N, generation of p40 MET was strongly decreased (Figure $2 b$, left panel, lanes 2 and 6). Similar results were obtained in time course experiments following treatment with various apoptotic inducers, including anisomycin, tumor necrosis factor (TNF) $\alpha /$ cycloheximide and staurosporine (Figure 3).

Together, our results show that mutation of the C-terminal caspase site unfavors juxtamembrane cleavage and then p40

a

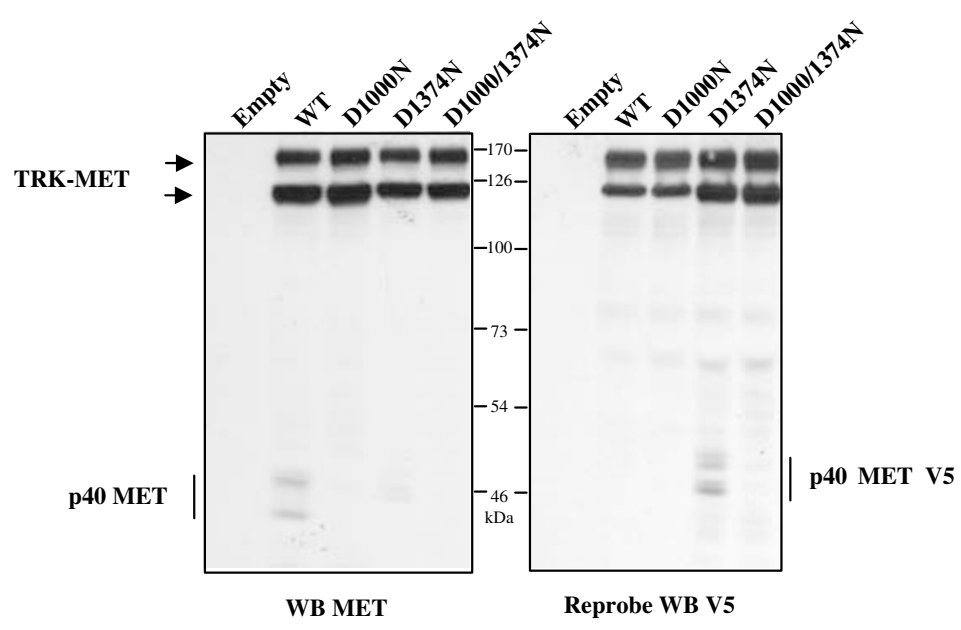

b

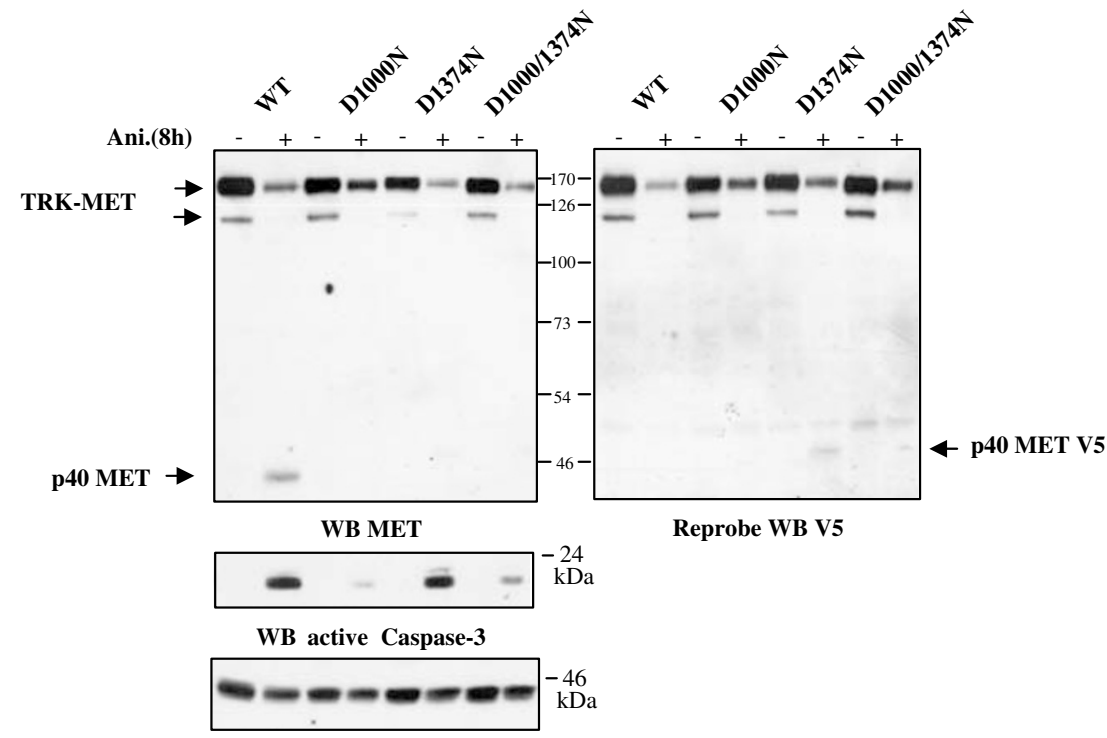

Reprobe WB ERK2


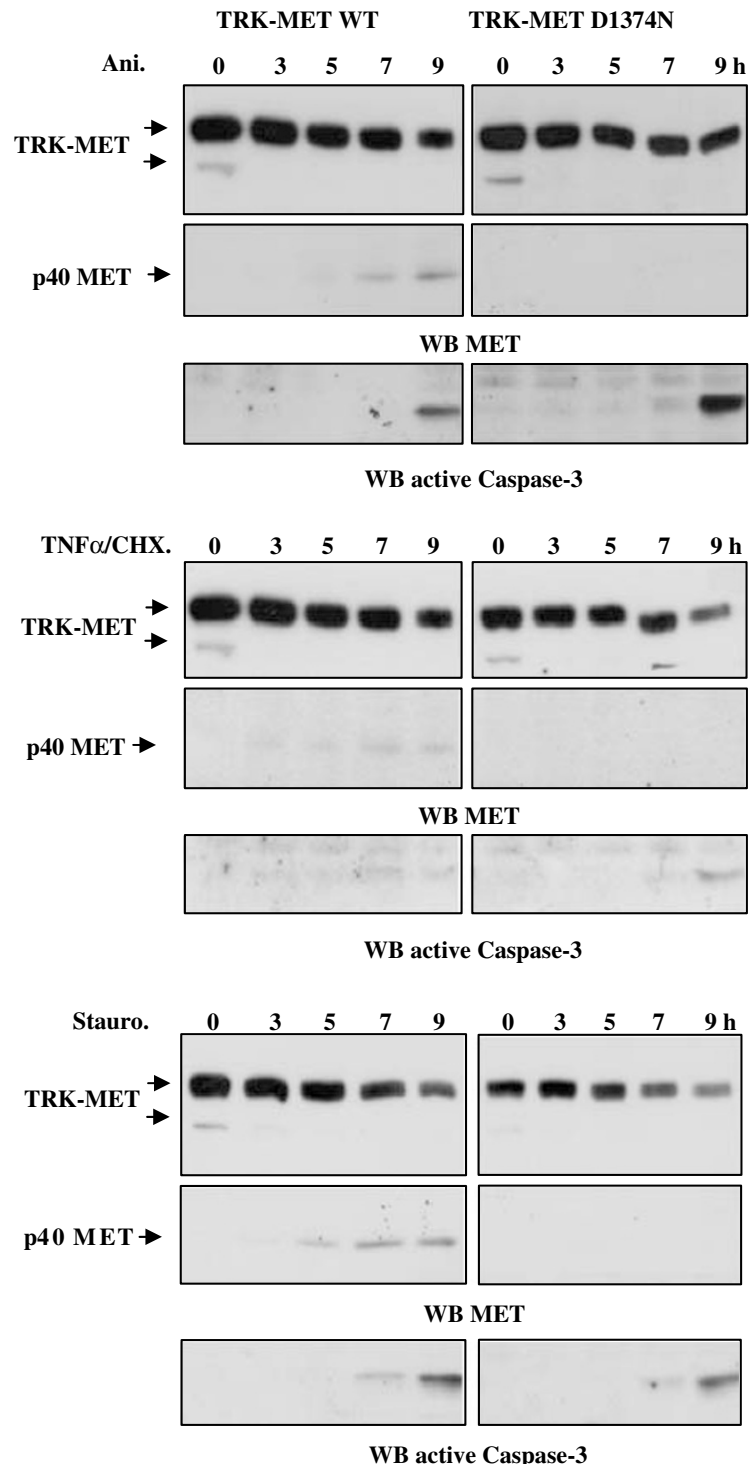

Figure 3 Generation of p40 MET induced during apoptotic process. MDCK epithelial cells expressing TRK-MET V5 WT and D1374N were treated for the indicated times with either anisomycin (Ani., $50 \mu \mathrm{M})$, TNF $\alpha(30 \mathrm{ng} / \mathrm{ml}) / \mathrm{cyclo}$ heximide (CHX, $10 \mu \mathrm{g} / \mathrm{ml})$ or staurosporine $(1 \mu \mathrm{M})$. For each condition, the same amount of proteins was resolved by $10 \%$ SDS-PAGE and analyzed by Western blotting using an anti-mouse MET antibody (top panel and middle panel). Lower part of the filter was analyzed by Western blotting using an anti-active caspase-3 antibody (lower panel). Arrows indicate positions of TRK-MET V5 and p40 MET fragment

MET generation, revealing the sequential organization of the cleavages. It is worth noting that sequential cleavages of MET are visualized only in cells following stress induction. In fact, during in vitro cleavage, mutation of the C-terminal site did not inhibit juxtamembrane cleavage, a likely consequence of efficient cleavage by excess of purified caspase.

Cleavage of MET receptor by caspase-3. To compare the ability of various caspases to cleave MET, cell extracts from MDCK cells expressing TRK-MET V5 were incubated with purified caspases. As shown in Figure $4 a$, only the caspase-3 was able to generate p40 MET. In addition, in extracts treated with caspase-3, neither p40 MET nor TRK-MET were detected using the anti-V5 antibody (Figure 4a, right panel), indicating that MET is an in vitro substrate of caspase-3 at both sites.

To assess in cells the role of caspase- 3 for the cleavage of MET, we transfected TRK-MET receptors in normal MCF-7 cells, which do not express caspase- 3 and in MCF-7 cells in which functional caspase-3 was reintroduced (MCF-7/ caspase-3) $^{28}$ (Figure 4b). In MCF-7/caspase-3 cells, p40 MET detection was strongly increased in comparison to normal MCF7 (Figure 4b, left panel). It should be noted that transfection of TRK-MET without additional stress was sufficient to induce generation of p40 MET, which was abolished by the caspase inhibitor (Supplementary data, Figure S1). The C-terminal cleavage was effective as well, as p40 MET was not detected using the anti-V5 antibody (Figure $4 \mathrm{~b}$, right panel). This demonstrates that caspase-3 favors cellular cleavage of MET.

Juxtamembrane and C-terminal cleavages of the human MET receptor. The C-terminal tail of MET receptor is poorly conserved (Figure 5a). In zebra fish and xenopus, a potential caspase motif was not found, whereas in chicken, dog and mouse, a consensual caspase motif is present (DXXD). In ape and human, the site appears to be duplicated (DXXDDXXD).

We found that anti-MET antibodies directed against the C-terminal tail of the human receptor were not able to recognize truncated MET from the D1376 of the C-terminal caspase site (Supplementary data, Figure S3A). Using these antibodies, we checked whether human p40 MET is cleaved in C-terminal. We transiently transfected MCF-7/caspase-3 cells with full-length human MET WT, kinase dead or mutated in the juxtamembrane caspase site. Using an anti-MET antibody recognizing the kinase domain, the WT and kinase dead MET receptors and their p40 MET fragments were detected. As expected, the fragment was not generated from the juxtamembrane caspase site mutant (Figure 5b, left panel). In contrast, using the anti-human MET antibody recognizing the C-terminal extremity, the full-length MET were detected, whereas p40 MET fragments were not (Figure 5b, right panel). These results show that, similarly to mouse MET, human p40 MET is cleaved in its C-terminal extremity.

In order to follow C-terminal and juxtamembrane endogenous cleavages of human MET during apoptosis, human epithelial cells from cervical carcinoma (HeLa cells) were treated with anisomycin and lyzed every hour. Western blot using anti-MET kinase revealed both full-length MET, which detection decreases only slightly along apoptosis, and p40 MET, generated from $1 \mathrm{~h}$ after treatment (Figure $5 \mathrm{c}$, left panel). In contrast, reprobe with anti-MET C-terminal antibody showed strong decrease of full-length MET detection along apoptosis and absence of p40 MET detection. Inversion of the order of probing between the antibodies gave similar results (Supplementary Data, S3B). These results confirm the C-terminal cleavage of human p40 MET and further demonstrate the existence of a membrane anchored MET receptor C-terminally truncated, which becomes the major form along apoptosis. 
a



b

MCF7

MCF7 Caspase-3

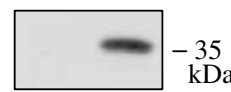

WB Caspase-3

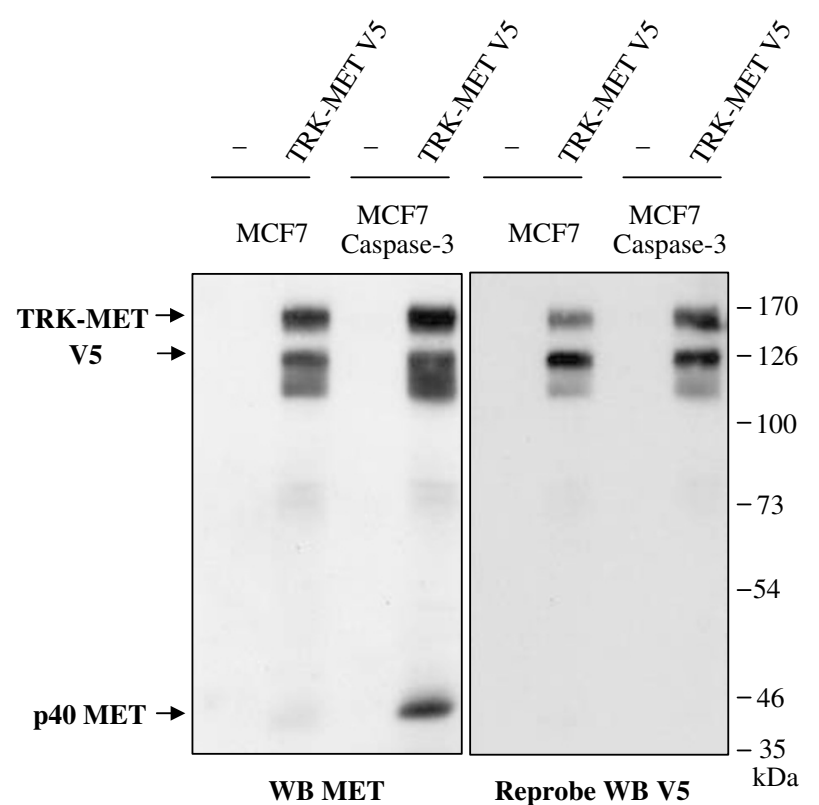

Figure 4 Caspase-3 cleaves the MET receptor. (a) Cell extracts of MDCK, stably transfected with the TRK-MET V5 WT chimera, were incubated with purified caspase-3, $-6,-7,-8$ or -9 . Samples were resolved by $10 \%$ SDS-PAGE and analyzed by Western-blotting using an antibody directed against mouse MET (left panel). The filter was stripped and reprobed using an anti-V5 antibody (right panel). (b) MCF-7 and MCF-7/caspase-3 cells were transiently transfected with vectors either empty or expressing TRKMET V5 WT. The following day, cells were lyzed. For each condition, the same amount of proteins was resolved by $10 \%$ SDS-PAGE and analyzed by Western blotting using an anti-mouse MET antibody (left panel). The filter was stripped and reprobed using an anti-V5 antibody (right panel). Western blotting using an anti-caspase-3 antibody was performed to assess expression of caspase-3 in MCF-7 and MCF-7/caspase-3. Arrows indicate positions TRK-MET and p40 MET fragment

C-terminal cleavage of p40 MET enhances its proapoptotic activity. In order to evaluate the biological relevance of the C-terminal truncation of p40 MET, we engineered a p40 MET long (from the juxtamembrane cleavage site to the C-terminal end) and p40 MET small (from the juxtamembrane to the C-terminal cleavage site). Immunofluorescence analysis revealed expression of p40 MET constructs both in cytoplasm and nucleus of transiently transfected NIH3T3. p40 MET-expressing cells were rounded and Hoechst staining showed characteristic signs of apoptosis, with either strong decrease of DNA contents or condensed DNA (Figure 6a, top panels). Interestingly, about $17 \%$ of p40 MET small-transfected cells were positive for active caspase- 3 staining, whereas $12 \%$ of active caspase-3positive cells were observed in p40 MET long-expressing cells, indicating that the C-terminal cleavage enhances the proapoptotic activity of the fragment (Figure 6a, lower panels). p40 MET small kinase dead-expressing cells displayed normal morphology, with percentage of activecaspase-3 positive cells corresponding to basal apoptosis in transfected cells. Similar results were obtained by counting the apoptotic nuclei in Hoechst staining. Cells expressing TPR-MET, the oncogenic form of MET, displayed normal morphology with level of cell death similar to p40 MET kinase dead (Figure 6b), indicating that ectopic expression of constitutive active MET kinase does not lead to apoptosis.

To assess these results, HEK293 cells were transfected with p40 MET constructs and selected with G418, as the expression vector contains this antibiotic resistance gene. After 10 days of selection, non-transfected and p40 MET 


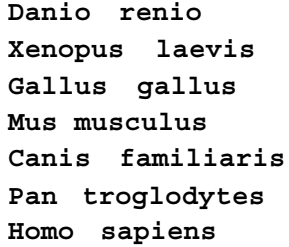

\begin{abstract}
GE HY ILLNT TYVNIDKMTPYPSLISSQSNLDRDCCT GE HYVLFNA TYVNIKCAAPYPSLLSPEGNIEFS IDT GE HYVHVNA TYVNVKCVAPYPSLLSSQDNTDMDVDT GE HYVHVNA TYVNVKCVAPYPSLLPSQDNIDGEGNT GE HYVHVNA TYVNVKCVAPYPSLLSSQDNIDGEGDT GE HYVHVNA TYVNVKCVAPYPSLLSSEDNADDEVDTRPASFWETS GE HYVHVNA TYVNVKCVAPYPSLLSSEDNADDEVDTRPASFWETS
\end{abstract}

b

MCF-7 caspase-3 Cells

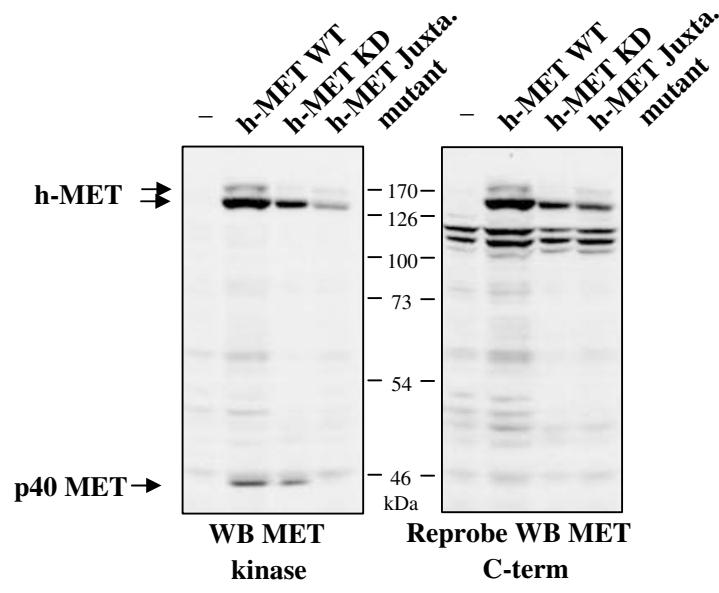

C

Hela Cells

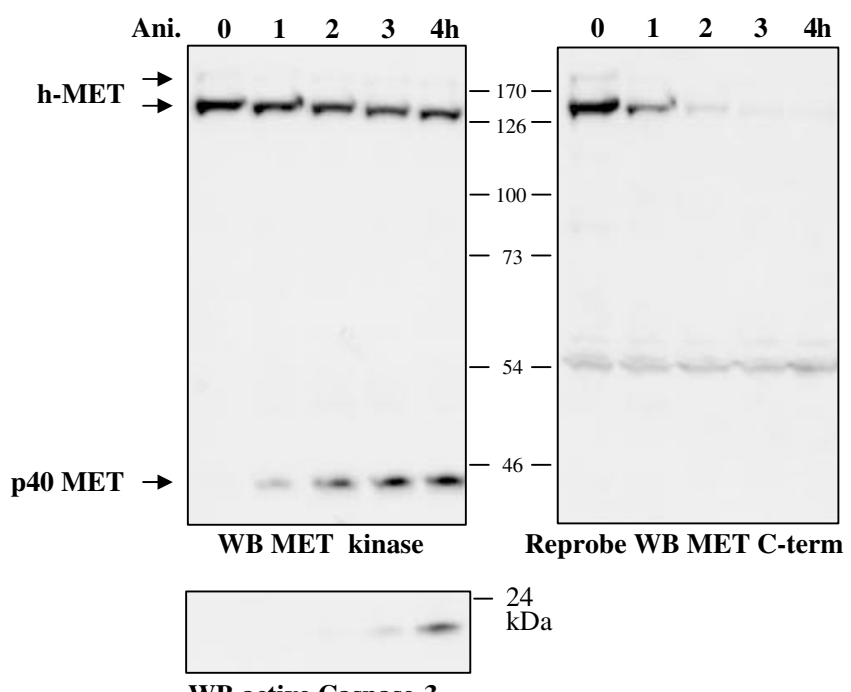

WB active Caspase-3

Figure 5 Human MET is cleaved by caspases in its C-terminal extremity. (a) Alignment of the amino-acid sequences of Danio renio, Xenopus laevis, Gallus gallus, Mus musculus, Canis familiaris, Pan troglodytes and Homo sapiens MET tyrosine kinase receptor. The tyrosine residues of the C-terminal multi-substrate binding site are in bold and the putative caspase sites are in bold and underlined. (b) Caspase-3 reconstituted MCF-7 cells were transiently transfected with $1 \mu \mathrm{g} / \mathrm{ml}$ of vector either empty or expressing human-MET WT, kinase dead (KD) or uncleavable mutant (Juxta. Mutant) in which the valine residue V1001 of the juxtamembrane cleavage site was replaced by alanine (V1001 in the human sequence corresponds to V999 in the murine sequence). The following day, cells were lyzed. For each condition, the same amount of proteins was resolved by $10 \%$ SDS-PAGE and analyzed by Western blotting using an antibody directed against the kinase domain of MET (left panel). The filter was stripped and reprobed using an antibody recognizing the C-terminal extremity of human MET (C-28 antibody) (right panel). Arrows indicate positions of immature and mature MET and p40 MET fragment. (c) HeLa cells were treated for the indicated times with anisomycin (Ani., $50 \mu \mathrm{M}$ ). For each condition, the same amount of proteins was resolved by $10 \%$ SDSPAGE and analyzed by Western blotting using an antibody directed against the kinase domain of MET (left panel). The filter was stripped and reprobed using an antibody recognizing the C-terminal extremity of human MET (C-12 antibody) (right panel). Lower part of the filter was analyzed by Western blotting using an anti-active caspase-3 antibody (lower panel). Arrows indicate positions of immature and mature MET and p40 MET fragment 
transfected cells died, whereas more than $60 \%$ of cells transfected with p40 MET kinase dead survived, using empty vector as a reference (Figure $6 \mathrm{c}$ ). In addition, we found that p40 MET small was more potent than p40 MET long to induce cell death. This effect was even stronger with p40 MET D1371N, suggesting that cell death induced by p40 MET long is in part the consequence of further $\mathrm{C}$-terminal cleavage. Two days following transfection and before G418 selection, p40 MET expression was checked (Figure 6d). At this stage, all the p40 MET were expressed and in contrast to p40 MET kinase dead, p40 MET long and small were detected as a smear, corresponding to their phosphorylated and nonphosphorylated forms (Figure 6d). In the majority of experiments, p40 MET kinase dead is less expressed that the p40 MET WT, a likely consequence of its instability. This could affect the cell death induced in HEK293 cells. However, we show in Supplementary Figure S4 that when p40 MET WT and kinase dead are expressed at similar level, we still observed efficient survival with p40 MET kinase dead. Overall, these results demonstrate that the $\mathrm{C}$-terminal cleavage of $\mathrm{p40} \mathrm{MET}$ fragment enhances its proapoptotic activity.

Mutation of C-terminal caspase site prevents cell death induced by mild stress. Generation of p40 MET can be prevented by mutations in the juxtamembrane region (D1000N) and C-terminal tail (D1374N). However, TRKMET D1000N cells display constitutive scattered phenotype (Supplementary data, Figure S2) and were resistant to apoptosis (Figure 2b). In contrast, cells expressing TRK-MET WT and TRK-MET D1374N displayed normal islet organization and scattered similarly in response to NGF and HGF/SF (Figure 7a). In addition, in response to NGF, TRK-MET WT and D1374N were similarly able to recruit the signaling protein GRB2 and activate the mitogen-activated protein kinase (MAPK) extracellular-regulated kinase (ERK) (Figure $7 \mathrm{~b}$ ). These results indicate that $\mathrm{D} 1374 \mathrm{~N}$ mutation does not modify basal and ligand-induced activity of TRKMET chimera. We therefore used the TRK-MET D1374N cells to evaluate the involvement of p40 MET generation in apoptosis.

In order to evaluate the consequence of p40 MET generation during the apoptotic response, we treated TRKMET WT or TRK-MET D1374N cells with a low dose of anisomycin. In this mild stress condition, TRK-MET WT cells began to detach by day 3 and all cells died by day 7 (Figure 7d). This cell death correlated with generation of the p40 MET fragment and caspase-3 activation (Figure 7c). In contrast, in TRK-MET D1374N cells, anisomycin treatment did not induce cell detachment, and caspase-3 or p40 MET were not detected even after 7 days. Therefore, the prevention of C-terminal cleavage of MET and subsequent decreased of $\mathrm{p} 40 \mathrm{MET}$ generation allowed resistance to cell death.

\section{Discussion}

In this report, we show that the MET tyrosine kinase receptor is cleaved during apoptosis in a caspase-dependent manner in both its juxtamembrane and C-terminal regions. Mutation analysis in mouse MET demonstrates that these cleavages occur at aspartic acid 1000 and 1374. The C-terminal cleavage generates an undetectable fragment constituted by the last five amino acids of mouse MET. Nonetheless, this cryptic cleavage was evidenced using a C-terminal tagged version of the TRK-MET receptor, in which the loss of the C-terminal V5 epitope enlightens the cleavage.

The amino-acid sequence of the C-terminal extremity is poorly conserved along evolution (Figure 5a). However, we demonstrated that mouse and human MET receptors are cleaved by caspases in this sequence, within a functional caspase site. Sequences analysis suggests a strengthening of the C-terminal caspase site according to animal species. Indeed, no consensual caspase site was found in the Cterminal tail of fishes and xenopus MET, this site (DXXD) is present in chicken, dog and mouse and is duplicated in ape and human (DXXDDXXD). Thus, although the extreme C-terminal tail of MET is poorly conserved, we identified a functional caspase site, which allows cleavage of MET during apoptosis.

Although the C-terminal cleavage eliminates only the last five amino acids of mouse MET, it has strong consequences on the mechanisms by which p40 MET is generated. First, we evidence a hierarchical organization of the cleavages, with the C-terminal cleavage favoring the juxtamembrane one. These two cleavages may therefore correspond to a double lock capable to prevent generation of p40 MET. As a second consequence of the double cleavage, a p40 MET fragment shortened of the last five amino acids is generated and is more potent to induce apoptosis. Together, these results demonstrate that the $\mathrm{C}$-terminal cleavage is involved in the reshaping of the MET receptor to a proapoptotic factor.

The identification of the C-terminal cleavage and its functional consequences on p40 MET suggests that the Cterminal extremity is a regulatory domain. For some tyrosine kinase receptors, C-terminal tails were evidenced as negative regulatory domains. For instance, deletion of the C-terminal sequences of Tie2 or platelet-derived growth factor beta

Figure 6 C-terminal cleavage enhances cell death induced by p40 MET. (a and $\mathbf{b})$ NIH3T3 cells were transiently transfected with vectors expressing either p40 MET small wild-type (p40 MET small), p40 MET small kinase dead (p40 MET KD), p40 MET long or TPR-MET. Forty-eight hours after transfection, nuclei were detected using Hoechst staining (Hoechst, Blue staining) and immunofluorescence was performed using an anti-MET antibody (Anti-MET, green staining) and an anti-cleaved caspase-3 (Anti-cleaved Caspase-3, red staining). White arrows indicate representative cells expressing transfected p40 MET. Percentage of caspase-3 positive cells and apoptotic nuclei (condensed DNA) over MET transfected cells was determined. At least 200 cells were counted per well in three different wells $(n=3 ; \pm$ S.D.). (c) HEK293 cells, cultured in six-well plates, were transfected or not with empty vector or vector expressing p40 MET small, p40 MET small KD, p40 MET long or p40 MET long D1371N. Two days later, cells were splited into four $100-\mathrm{mm}$ dishes and the remaining cells were lyzed for Western blot analysis. Cells were then selected 10 days with G418 and counted. Results are represented as percentage of surviving cells using empty vector transfection as reference $(n=3 ; \pm$ S.D.). One dish from each condition was also stained and shown (lower panel). (d) Cell extracts prepared the second day after transfection were resolved by $10 \%$ SDS-PAGE and analyzed by Western blotting using an anti-mouse MET antibody to assess expression from the transfected vector (top panel). The filter was stripped and reprobed using an anti-phospho MET antibody (lower panel) 
receptor (PDGF $\beta$-R) potentiates their tyrosine kinase activity. ${ }^{29,30}$ For MET an inhibitory role of the C-terminal tail has been proposed, based on the fact that a peptide centered on the
C-terminal multi-substrate binding site inhibited the kinase activity. ${ }^{31}$ It is then attractive to propose that the C-terminal cleavage of MET could relieve an inhibitory conformation, a
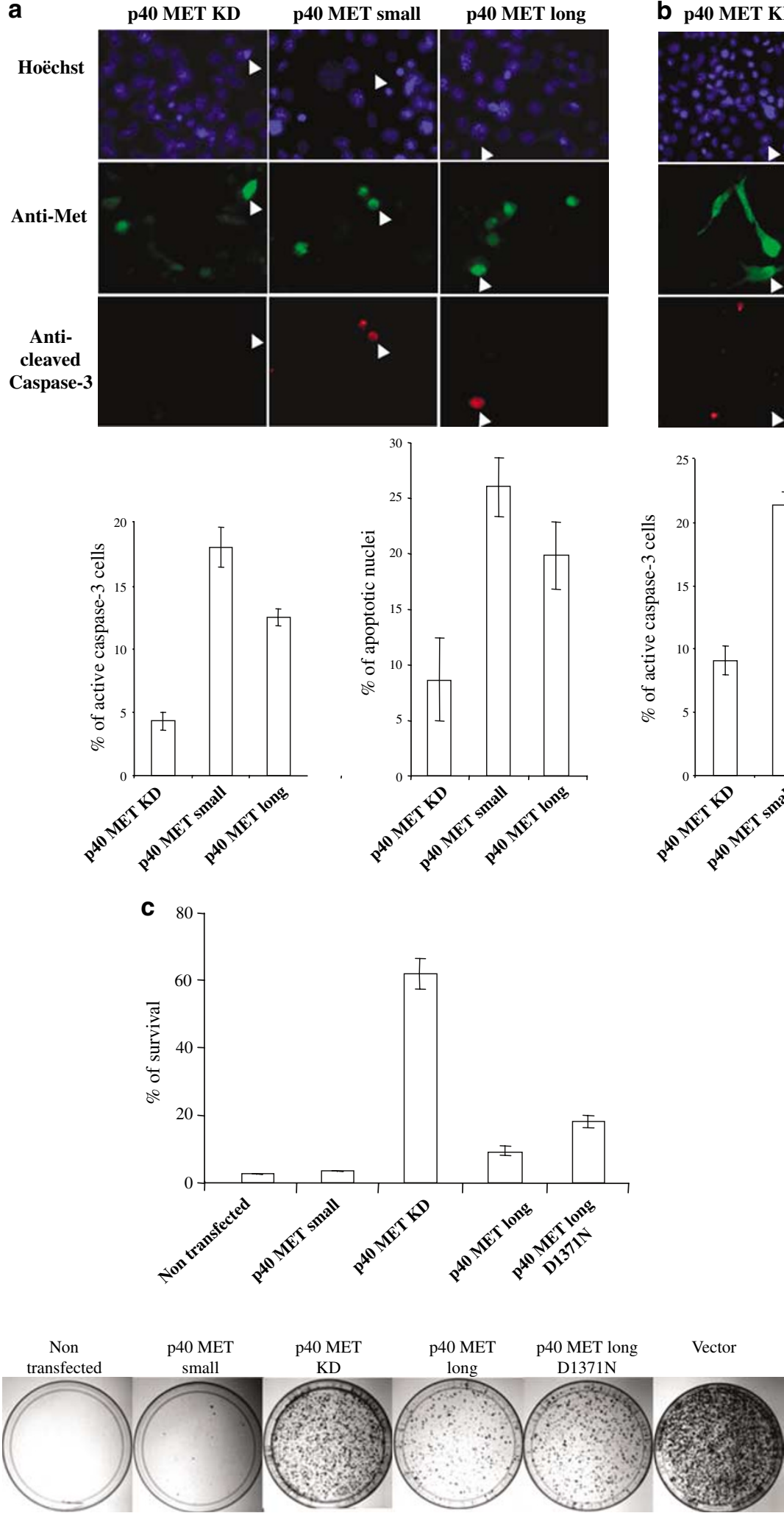
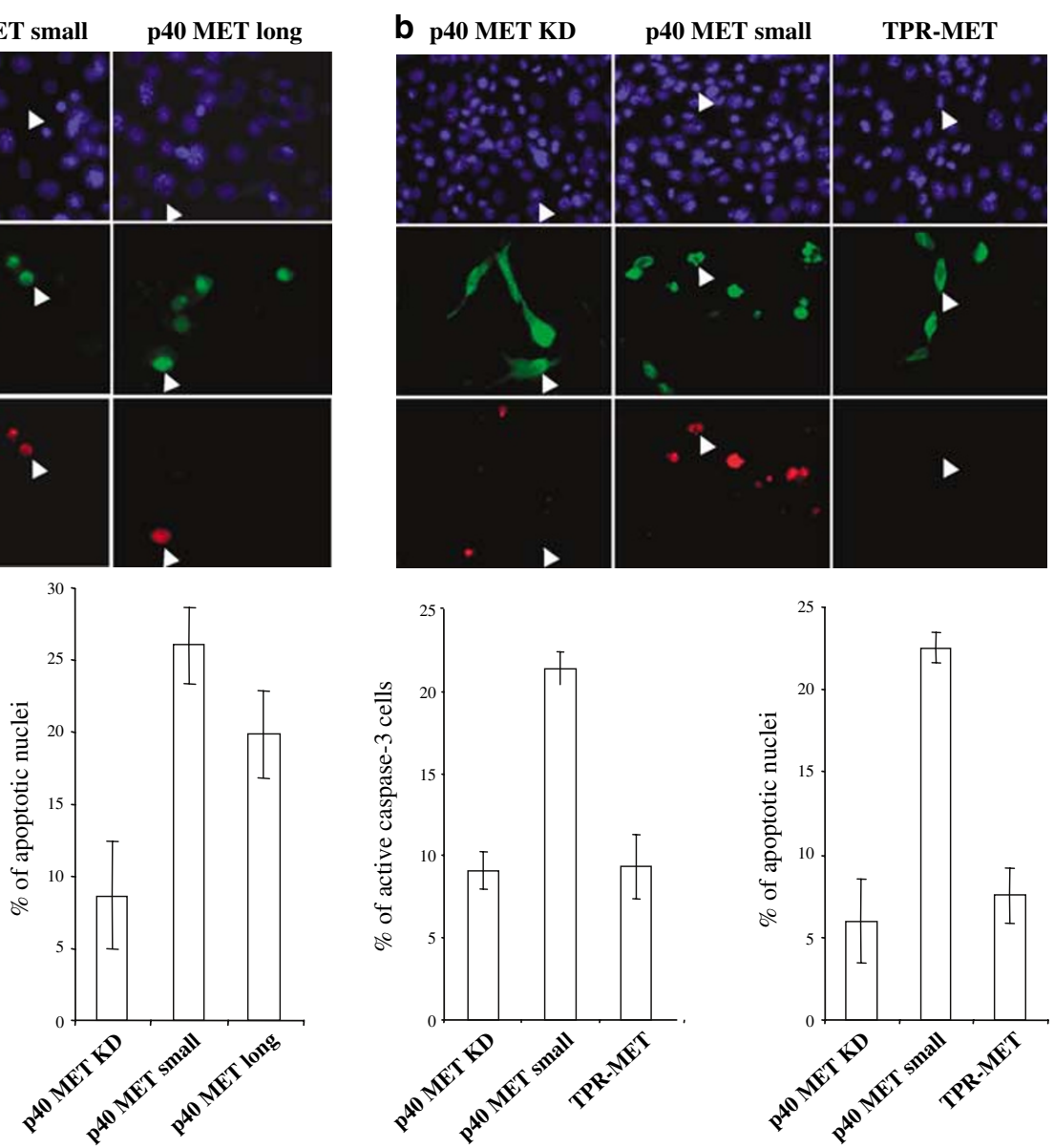

d

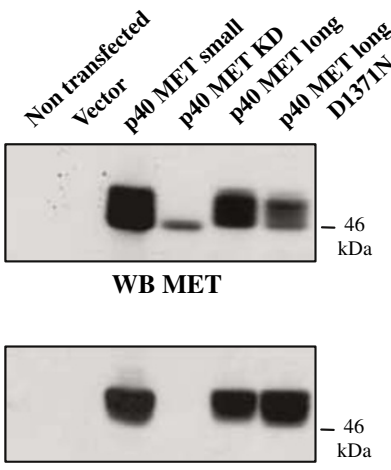

Reprobe WB phospho-MET

Figure 6 
which could be involved in induction of the apoptotic response.

Our demonstration that p40 MET is apoptotic raise the question whether it contributes to amplification of cells death. The TRK-MET D1000N cells were useless for this purpose. Indeed, the aspartic acid D1000 belongs to the CBL binding motif (DYR), which contributes to MET ubiquitination and downregulation in response to HGF/SF. ${ }^{27}$ Mutation of tyrosine 1001 or aspartic acid 1000 decreases CBL binding, leading to constitutive scattering of MDCK cells ${ }^{25,27}$ and resistance to apoptosis. However, in this study, by identifying an additional caspase cleavage site, we generated a second mutant in which p40 MET generation is prevented. In contrast to D1000N mutation, D1374N mutation did not modify MET properties, including its ability to mediate RAS-ERK signaling activation and cell scattering. Under mild stress conditions, TRK-MET D1374N cells displayed prolonged cell survival compared to TRK-MET WT cells, indicating that p40 MET generation amplifies cell death. This amplification of apoptosis was not observed in MDCK expressing TRK-MET WT and $\mathrm{D} 1374 \mathrm{~N}$, when high dose of anisomycin, which induced massive cell death within hours, was used. These results indicate that p40 MET generation is dispensable for induction of apoptosis induced by strong stress stimuli, whereas it is able to switch the cells to apoptosis in mild stress conditions. In this line, it is worth noticing that p40 MET is not a strong inducer of apoptosis, with level of apoptosis in p40 MET transfected cells not exceeding $20 \%$. We therefore conclude that p40 MET can act as an amplifier rather than as an inducer of apoptosis.

Although many caspase substrates are cleaved at several sites, ${ }^{32}$ the hierarchical organization of these cleavages is poorly defined. The Ras GTPase-activating protein (RasGAP) protein is cleaved at several sites by caspase-3, with the first cleavage occurring soon during apoptosis and favoring the second one. ${ }^{33,34}$ The first cleavage allows generation of an anti-apoptotic fragment, whereas the second cleavage converts it in smaller proapoptotic fragments. In this instance, sequential cleavage supports a model in which RasGAP functions as a sensor of caspase activity to determine whether cell will survive or not. ${ }^{35}$ In the case of MET, its sequential cleavages lead to the generation of a shortened MET, cleaved only in its C-terminal region. Although, following this first cleavage, the juxtamembrane cleavage allows generation of p40 MET, the shortened MET becomes along apoptotis the major form of membrane MET receptors. This novel form of MET potentially inducible by HGF/SF could acquire specific functions, which could be involved as well in the regulation of the balance survival/apoptosis mediated by the tyrosine kinase receptor MET.

\section{Materials and Methods}

Cytokines, drugs and cell cultures. Human recombinant HGF/SF was purchased from Peprotech and $\beta$-NGF and TNF- $\alpha$ from R\&D Systems. Anisomycin was purchased from Calbiochem, cycloheximide from ICN Biomedicals and staurosporine from Sigma. The general caspase inhibitor, Z-Val-Ala-Asp (OMe)fluoromethyl ketone (zVAD-FMK) was purchased from Kamiya Biomedical Company. MDCK epithelial cells, 293 human embryonic renal epithelial cell line (HEK293) and HeLa cells were cultured in Dulbecco's modified Eagle's medium (DMEM, Invitrogen) supplemented with $10 \%$ heat-inactivated fetal calf serum (FCS, Invitrogen) and antibiotics. MCF-7 cells and MCF-7/caspase-3 cells (kindly provided by Reiner Jänicke, University of Dusseldorf, Germany) were cultured in RPMI 1640 (Gibco) supplemented with 10\% FCS and antibiotics. Mouse fibroblasts NIH3T3 were cultured in DMEM medium supplemented with $10 \%$ heat-inactivated calf serum (Hyclone). Cells were cultured at $37^{\circ} \mathrm{C}$ in water-saturated $5 \% \mathrm{CO}_{2}$ atmosphere.

Plasmid constructions. The TRK-MET V5-His chimeras were described previously. ${ }^{19}$ Briefly, the original TRK-MET chimeras cloned in pBAT vector, which allow expression of extracellular TRKA receptor fused to the transmembrane and cytoplasmic region of mouse MET, ${ }^{25}$ were cloned in pcDNA $3.1 \mathrm{~V} 5$-His $\mathrm{C}$ plasmid (Invitrogen). The TRK sequence, up to the BamHI restriction site, was cut out by digestion using Hindll and BamHI restriction enzymes and cloned into pcDNA 3.1 V5-His plasmid. The remaining TRK-MET sequence, from the BamHI restriction site to the $3^{\prime}$ end, was amplified by PCR using the primer containing the BamHI restriction site and primer containing the Xhol restriction site, using pBAT TRK-MET as template. The PCR product was subcloned into a pGEM plasmid (pGEM Easy kit; Stratagene). MET in which aspartic acid 1374 was replaced by an asparagine, was created using the QuickChange site-directed mutagenesis system from Stratagene, using pGEM MET WT or D1000N as template and the following primers: $5^{\prime}$-CCCAAGACAACATTAATGGCGAGGGG-3' and $5^{\prime}$-CCCCTCGCCATT AATGTTGTCTTGGG-3'. Insertion of the mutation was verified by sequencing. Finally, MET sequence from pGEM was inserted in pcDNA3 TRK using BamH1 and Xho1 restriction site. The other mutations were described previously. ${ }^{19}$

Full-length human MET, in which valine residue V1001 (V1001 in human sequence corresponding to V999 in murin sequence) of the juxtamembrane cleavage site was replaced by alanine, was created using the QuickChange sitedirected mutagenesis system, using pMT2 human MET WT (generously gift by Flavio Maina, IBDM, Marseille, France) as template and the following primers: $5^{\prime}-\mathrm{CA}$ AATGAATCTGCAGACTACCGAGCTAC- $3^{\prime}$ and $5^{\prime}$-GTAGCTCGGTAGTCTGCAGA TTCATTTG- $3^{\prime}$. Insertion of the mutation was verified by sequencing.

The N-terminal Flag p40 MET long was constructed as follows: the mouse MET from the juxtamembrane caspase site to the $\mathrm{C}$-terminal end was amplified by PCR using TRK-MET WT as template and the following primers: $5^{\prime}$-CAAATGAGTCTGG ATCCTACAGAGCTAC- $3^{\prime}$ containing the BamHI restriction site and the primer $5^{\prime}-\mathrm{C}$ CTCGAACTCGAGACCTCAAGTGTTCCC- $3^{\prime}$ containing the Xhol restriction site. The N-terminal Flag p40 MET small and p40 MET small kinase dead version (p40 MET Small K1108A) were constructed as follows: the mouse MET from the juxtamembrane caspase site to the C-terminal caspase site was amplified by PCR using TRK-MET WT and TRK-MET K1108A as templates and the following primers: $5^{\prime}$-CAAATGAGTCTGGATCCTACAGAGCTAC- $3^{\prime}$ containing the BamHI restriction site and the primer $5^{\prime}$-TCTCGAGTTCCCCTCTCAATCAATGTTGTC- $3^{\prime}$ containing

Figure 7 Influence of the C-terminal caspase site mutation in cell death induced by mild stress. (a) MDCK epithelial cells expressing TRK-MET V5 WT and D1374N were seeded at low density. Two days later, cells were cultured for $24 \mathrm{~h}$ in the absence (-) or presence of $10 \mathrm{ng} / \mathrm{ml}$ of HGF/SF or $100 \mathrm{ng} / \mathrm{ml}$ of NGF and photographs were taken (magnification $\times 80)$. (b) MDCK epithelial cells $\left(1.10^{6}\right.$ cells $/ 100 \mathrm{~mm}$-dish) expressing or not TRK-MET V5 WT and D1374N were cultured over-night in DMEM-0\% FCS and stimulated or not $10 \mathrm{~min}$ with $200 \mathrm{ng} / \mathrm{ml}$ of NGF. For each condition, the same amount of whole cell lysat was resolved by $10 \%$ SDS-PAGE and analyzed by Western blotting using an anti-mouse MET antibody (first panel) or an anti-phosphorylated ERK1 and 2 (second panel) antibody. The filter was stripped and reprobed using an anti-ERK2 antibody (third panel). From the same extracts, immunoprecipitation was performed using a polyclonal antibody against mouse MET and processed for Western blotting using an anti-GRB2 antibody (last panel). (c) MDCK epithelial cells $\left(2.10^{5} \mathrm{cells} / 35 \mathrm{~mm}\right.$-dish), stably transfected with the TRK-MET V5 WT or D1374N were cultured 1 day in DMEM$10 \%$ FCS and treated with anisomycin (Ani., $0.3 \mu \mathrm{M}$ ). Every day, cells were lyzed and proteins were resolved by $10 \%$ SDS-PAGE and analyzed by Western blotting using an antibody directed against mouse MET (top panels). Similar extracts were resolved by a 12\% SDS-PAGE and Western blotting was performed using an anti-active caspase-3 antibody (lower panel). Arrows indicate positions of TRK-MET V5 and p40 MET. (d) Photographs were taken on light microscopy before lysis (magnification $\times 40)$ 
the Xhol restriction site. The sequences obtained were cloned using BamHI/Xhol in frame with Flag sequence in pcDNA3 vector.

The oncogene TPR-MET was constructed as follows: TPR-MET sequence was amplified by PCR using pXM139 SMS TPR-MET as template (generously gift by
Morag Park, McGill University, Montreal, Quebec, Canada) and the primers $5^{\prime}$-GCG CCGGCCTCGAGTCATGGCGGCGGTG-3' containing the Xhol restriction site and $5^{\prime}$-TCAGTCTAGATCTGATGCTCTGTCAG- $3^{\prime}$ containing the $X$ bal restriction site. The TPR-MET sequence was cloned in pcDNA3 vector using the Xhol/Xbal sites. a

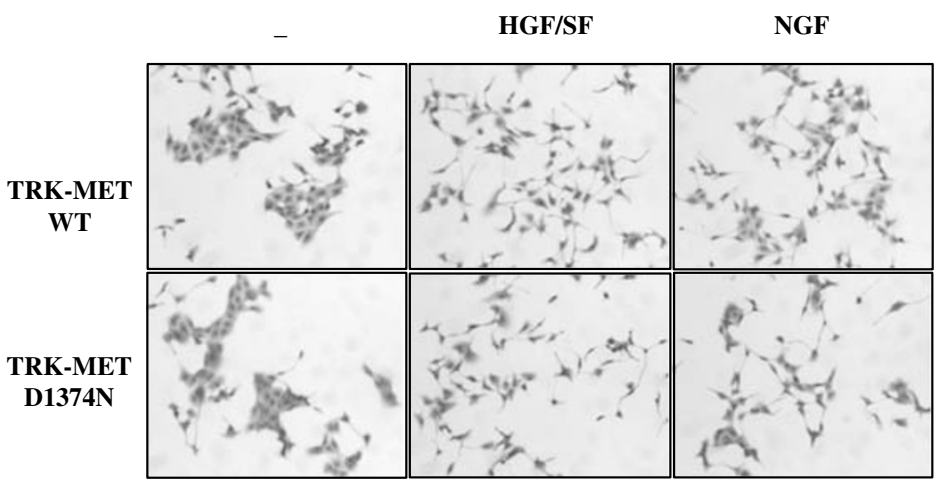

b

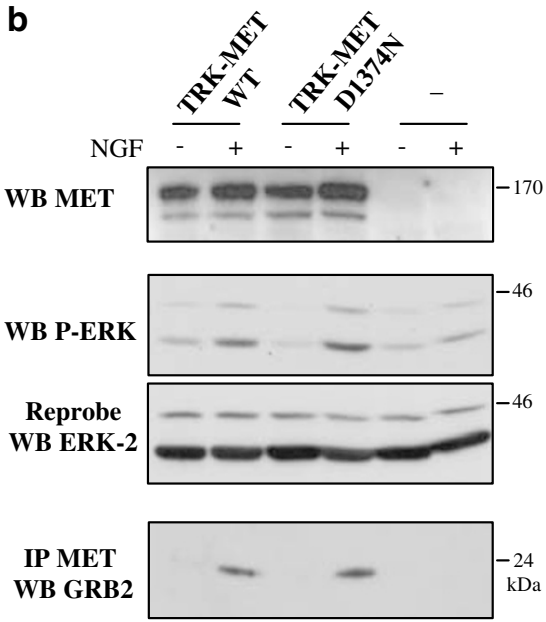

C TRK-MET WT TRK-MET D1374N

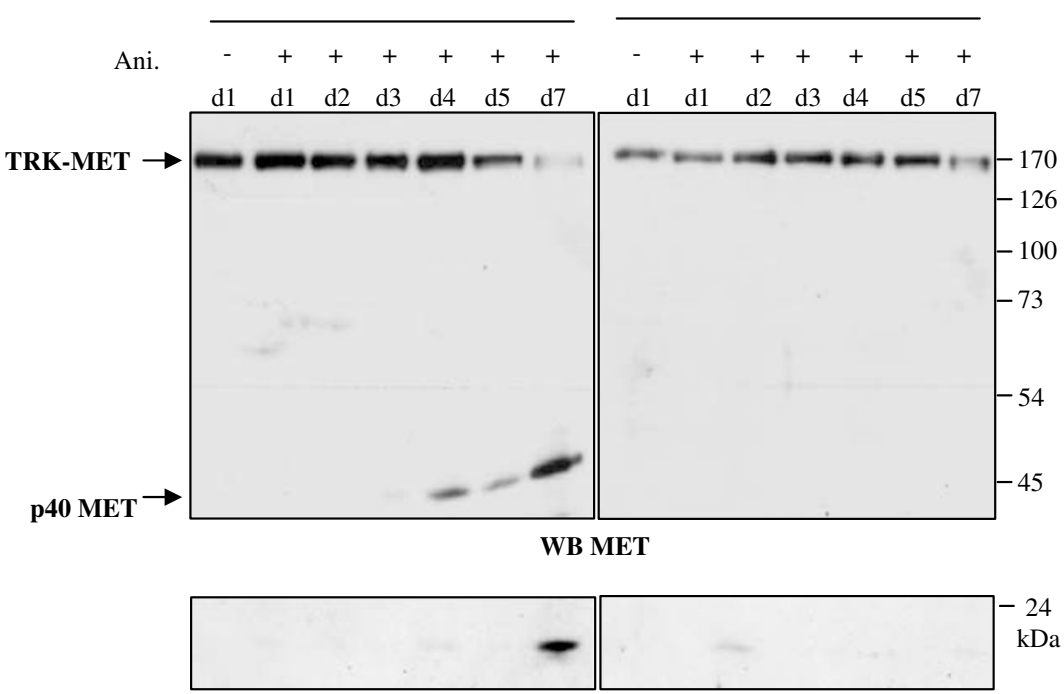

WB active Caspase-3

d

TRK-MET

WT
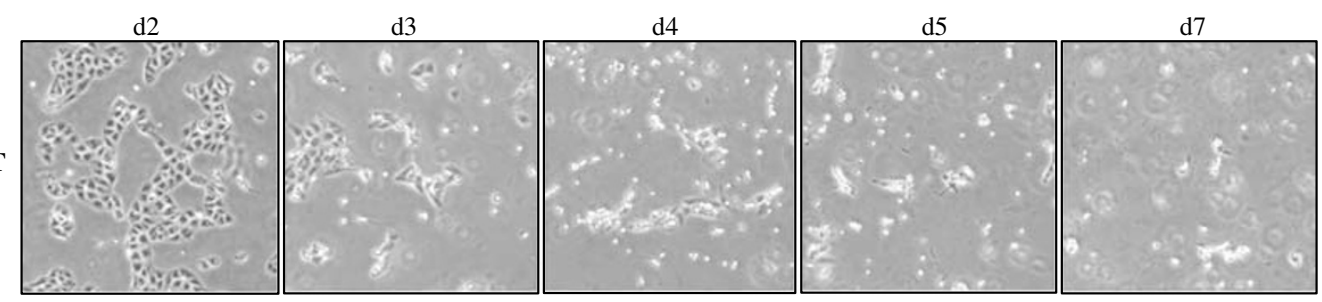

TRK-MET

D1374N
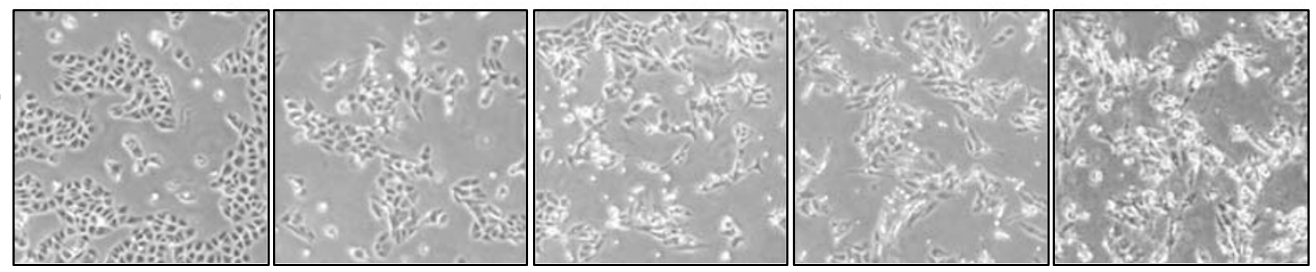

Figure 7 
The TPR-MET kinase dead (TPR-MET KD) in which lysine 1110 was replaced by arginine was created using the QuickChange site-directed mutagenesis system from Stratagene using pcDNA3 TPR-MET as template and the following primers: $5^{\prime}$-CACTGTGCTGTGGCATCCTTGAACAGAATC- $3^{\prime}$ and $5^{\prime}$-GATTCTGTTCAAGG ATGCCACAGCACAGTG-3'. TPR-MET truncated from aspartic acid 1376 (TPRMET $\delta \mathrm{Ct}$ ) was created using the QuickChange site-directed mutagenesis system using pcDNA3 TPR-MET as template and the following primers: $5^{\prime}$ GATAACGCTGATTAGTGCTAGTACTATGTC $3^{\prime}$ and $5^{\prime}$ GACATAGTACTAGCACTAATCAGCGTTATC $3^{\prime}$.

Antibodies. Mouse monoclonal antibody directed against mouse MET (B-2) and rabbit polyclonal antibodies against C-terminal region of human MET (C-28 and C-12), against mouse MET (SP-260) and against ERK2 (C-14) were purchased from SantaCruz Biotechnology. Mouse monoclonal antibodies directed against the kinase domain of MET (25H2) and directed against phosphorylated ERK and rabbit polyclonal antibody against cleaved caspase-3 were purchased from Cell Signaling Technology. Rabbit polyclonal antibody against phosphorylated tyrosines 1234 and 1235 of MET kinase domain was purchased from Upstate Biotechnology. Rabbit polyclonal antibody against caspase-3 was purchased from Stressgen Biotechnologies. Mouse monoclonal antibody directed against V5 tag was purchased from Invitrogen. Mouse monoclonal antibody against GRB2 was purchased from Transduction Laboratories. Peroxydase, fluorescein and rhodamine conjugated antibodies directed against rabbit and mouse IgG were purchased from Jackson Immunoresearch Labs.

Western blotting. MDCK and MCF-7 cells $\left(3.10^{5}\right.$ cells $/ 35 \mathrm{~mm}$-dish $)$ transfected or not were cultured 1 day in DMEM-10\% FCS and RPMI-10\% FCS respectively, and treated or not with anisomycin, TNF $\alpha / c y c l o h e x i m i d e$ or staurosporine in serum free medium. Adherent cells and cells in suspension, collected after centrifugation of the medium, were lyzed and protein concentration determined by Bio-Rad protein assay. Western blotting was performed as described previously. ${ }^{36}$ Results are representative of at least two experiments.

Trypan blue staining. MDCK cells were cultured in the same condition that described previously. Adherent cells, detached with trypsin, and cells in suspension, collected after centrifugation of the medium, were collected and stained with trypan Blue (Sigma) (PBS/trypan Blue, vol/vol) for $15 \mathrm{~min}$ at room temperature. Unstained cells (cells alive) and blue cells (dead cells) were counted in Malassez hematimeter.

Caspase cleavage reaction. Caspase cleavages using cell extract were performed as follows: MDCK cells stably transfected with the TRK-MET chimeras $\left(3.10^{5} \mathrm{cells} / 35 \mathrm{~mm}\right.$-dish) were cultured 1 day in DMEM-10\% FCS and then lyzed in $100 \mu \mathrm{l}$ of caspase buffer (20 mM PIPES pH 7.2; $100 \mathrm{mM} \mathrm{NaCl} ; 1 \%$ Chaps; $10 \%$ sucrose; $5 \mathrm{mM}$ DTT; $0.05 \mathrm{mM}$ EDTA). Cell extracts were incubated $4 \mathrm{~h}$ at $37^{\circ} \mathrm{C}$ with $1 \mu \mathrm{l}$ of purified caspase. Proteins were then resolved on sodium dodecyl sulfatepolyacrylamide gel electrophoresis (SDS-PAGE) and submitted to Western blotting. ${ }^{36}$ Purified active caspases were generously provided by $\mathrm{Dr}$ GS Salvesen (The Burnham Institute, La Jolla, CA, USA). Titration of the active recombinant caspases have been obtained using in vitro cleavages against synthetic substrates as described previously ${ }^{37}$ (Caspase-3, $13.9 \mu \mathrm{M}$; Caspase-6, 7.5 $\mu \mathrm{M}$; Caspase-7, $19.7 \mu \mathrm{M}$; Caspase-8, $15 \mathrm{mM}$; Caspase-9, $41.5 \mu \mathrm{M}$ ).

Transfections. Transient and stable transfections of MDCK cells were performed as described previously using the lipofection method. ${ }^{26}$ For transient transfection of NIH3T3 fibroblasts, $8.10^{4}$ cells were cultured in 12-well plates and were incubated with a mixture of DNA $(1 \mu \mathrm{g} / \mathrm{ml})$ and Lipofectamine (Invitrogen; $20 \mu \mathrm{g} / \mathrm{ml}$ ). MCF7 cells $\left(3.10^{5}\right)$ were cultured in six-well plates and were incubated with a mixture of DNA $(1.25 \mu \mathrm{g} / \mathrm{ml})$ and PEI/ExGen 500 (Euromedex).

Immunofluorescence. NIH3T3 cells $\left(80 \times 10^{3}\right.$ cells $/ 24 \mathrm{~mm}$-dish $)$ were cultured for 1 day in DMEM-10\% CS on glass coverslips and transiently transfected as described above. Forty-eight hours after transfection, cells were washed, fixed with $4 \%$ paraformaldehyde, permeabilized with $0.1 \%$ triton $\mathrm{X}-100$, and blocked with $0.2 \%$ casein for $30 \mathrm{~min}$. Cells were incubated $60 \mathrm{~min}$ with a combination of mouse anti-Met antibody $(1: 200)$ and rabbit anti-active caspase-3 antibody $(1: 200)$. Cells were then washed and incubated with a combination of fluorescein-conjugated anti-mouse $\mathrm{lgG}(7 \mu \mathrm{g} / \mathrm{ml})$ and rhodamine-conjugated anti-rabbit lgG $(7 \mu \mathrm{g} / \mathrm{ml})$. Cell nuclei were counterstained using Hoechst 33258 . Coverslips were mounted with Glycergel mounting medium (Dako) and fluorescence examined using a Zeiss Axioplan2. Results presented are representative of three experiments.
Colony-formation assay. For the colony formation assay, $6 \times 10^{5}$ HEK293 cells/well were plated in six-well plates, and the next day transient transfections were performed using the polyethyleneamine Exgen 500 procedure (Euromedex) using $1 \mu \mathrm{g}$ of DNA/well. Two days after transfection, cells were split into three $100-\mathrm{mm}$ dishes containing DMEM-10\% FCS, and the next day the medium was supplemented with $1.1 \mathrm{mg} / \mathrm{ml} \mathrm{G} 418$ (Gibco). After 2 weeks, cells were counted.

Acknowledgements. This work was supported by the CNRS, the Institut Pasteur de Lille, INSERM, University of Lille 1 and University of Lille 2 and by grants from, the 'Fondation de France' (FdF), the Feder and the 'Ligue contre le Cancer, comité Nord'. BF was supported by a 'Institut Pasteur/Région Nord- Pas de Calais' fellowship, JD by a 'Association pour la Recherche sur le Cancer' (ARC) fellowship and ZJ by Fondation de France fellowship.

1. Nakamura $T$, Nawa $K$, Ichihara A. Partial purification and characterization of hepatocyte growth factor from serum of hepatectomized rats. Biochem Biophys Res Commun 1984; 122: $1450-1459$

2. Naldini L, Weidner KM, Vigna E, Gaudino GK, Bardelli A, Ponzetto C et al. Scatter factor and hepatocyte growth factor are undistinguishable ligands for the MET receptor. EMBO J 1991; 10: 2867-2878.

3. Stoker M, Perryman M. An epithelial scatter factor released by embryo fibroblasts. J Cell Sci 1985; 77: 209-223.

4. Longati P, Bardelli A, Ponzetto C, Naldini L, Comoglio PM. Tyrosines1234-1235 are critical for activation of the tyrosine kinase encoded by the MET proto-oncogene (HGF receptor). Oncogene 1994; 9: 49-57.

5. Ponzetto C, Bardelli A, Zhen Z, Maina F, dalla Zonca P, Giordano S et al. A multifunctional docking site mediates signaling and transformation by the hepatocyte growth factor/scatter factor receptor family. Cell 1994; 77: 261-271.

6. Weidner KM, Dicesare S, Sachs M, Brinkmann V, Behrens J, Birchmeier W. Interaction between gab1 and the c-Met receptor tyrosine kinase is responsible for epithelial morphogenesis. Nature 1996; 384: 173-176.

7. Birchmeier C, Birchmeier W, Gherardi E, Vande Woude GF. Met, metastasis, motility and more. Nat Rev Mol Cell Biol 2003; 4: 915-925.

8. Crepaldi T, Prat M, Giordano S, Medico E, Comoglio PM. Generation of a truncated hepatocyte growth factor receptor in the endoplasmic reticulum. J Biol Chem 1994; 269: $1750-1755$

9. Gandino L, Longati P, Medico E, Prat M, Comoglio PM. Phosphorylation of serine 985 negatively regulates the hepatocyte growth factor receptor kinase. J Biol Chem 1994; 269 : 1815-1820.

10. Peschard $P$, Fournier TM, Lamorte L, Naujokas MA, Band H, Langdon WY et al. Mutation of the $\mathrm{c}-\mathrm{Cb}$ TKB domain binding site on the Met receptor tyrosine kinase converts it into a transforming protein. Mol Cell 2001; 8: 995-1004.

11. Villa-Moruzzi E, Puntoni F, Bardelli A, Vigna E, De Rosa S, Comoglio PM. Protein tyrosine phosphatase PTP-S binds to the juxtamembrane region of the hepatocyte growth factor receptor Met. Biochem J 1998; 336: 235-239.

12. Vigna $E$, Gramaglia $D$, Longati $P$, Bardelli A, Comoglio PM. Loss of the exon encoding the juxtamembrane domain is essential for the oncogenic activation of TPR-MET. Oncogene 1999; 18: 4275-4281.

13. Kosai K, Matsumoto K, Nagata S, Tsujimoto Y, Nakamura T. Abrogation of Fas-induced fulminant hepatic failure in mice by hepatocyte growth factor. Biochem Biophys Res Commun 1998; 244: 683-690.

14. Bowers DC, Fan S, Walter KA, Abounader R, Williams JA, Rosen EM et al. Scatter factor/ hepatocyte growth factor protects against cytotoxic death in human glioblastoma via phosphatidylinositol 3-kinase- and AKT- dependent pathways. Cancer Res 2000; 60: $4277-4283$.

15. Xiao GH, Jeffers M, Bellacosa A, Mitsuuchi Y, Vande Woude GF, Testa JR. Anti-apoptotic signaling by hepatocyte growth factor/Met via the phosphatidylinositol 3-kinase/Akt and mitogen-activated protein kinase pathways. Proc Natl Acad Sci USA 2001; 98: 247-252.

16. Bladt F, Riethmacher D, Isenmann S, Aguzzi A, Birchmeier C. Essential role for the c-met receptor in the migration of myogenic precursor cells into the limb bud. Nature 1995; 376 : 768-771.

17. Schmidt C, Bladt F, Goedecke S, Brinkmann V, Zschiesche W, Sharpe M et al. Scatter factor/hepatocyte growth factor is essential for liver development. Nature 1995; 373: 699-702.

18. Uehara Y, Minowa O, Mori C, Shlota K, Kuno J, Noda T et al. Placental defect and embryonic lethality in mice lacking hepatocyte growth factor/scatter factor. Nature 1995; 373: 702-705.

19. Tulasne D, Deheuninck J, Lourenco FC, Lamballe F, Ji Z, Leroy C et al. Proapoptotic function of the MET tyrosine kinase receptor through caspase cleavage. Mol Cell Biol 2004; 24: $10328-10339$

20. Degterev A, Boyce M, Yuan J. A decade of caspases. Oncogene 2003; 22: 8543-8567.

21. Sakahira $H$, Enari M, Nagata $S$. Cleavage of CAD inhibitor in CAD activation and DNA degradation during apoptosis. Nature 1998; 391: 96-99. 
22. Enari M, Sakahira $H$, Yokoyama $H$, Okawa $K$, Iwamatsu A, Nagata S. A caspaseactivated DNase that degrades DNA during apoptosis, and its inhibitor ICAD. Nature 1998 391: 43-50.

23. Sebbagh M, Renvoize C, Hamelin J, Riche N, Bertoglio J, Breard J. Caspase-3-mediated cleavage of ROCK I induces MLC phosphorylation and apoptotic membrane blebbing. Nat Cell Biol 2001; 3: 346-352.

24. Coleman ML, Sahai EA, Yeo M, Bosch M, Dewar A, Olson MF. Membrane blebbing during apoptosis results from caspase-mediated activation of ROCK I. Nat Cell Biol 2001 3: 339-345.

25. Weidner KM, Sachs M, Birchmeier W. Mutation of juxtamembrane tyrosine residue 1001 suppresses loss-of-function mutations of the met receptor in epithelial cells. Proc Natl Acad Sci USA 1995; 92: 2597-2601.

26. Tulasne D, Paumelle R, Weidner KM, Vandenbunder B, Fafeur V. The multisubstrate docking site of the MET receptor is dispensable for MET-mediated RAS signaling and cell scattering. Mol Biol Cell 1999; 10: 551-565.

27. Peschard P, Ishiyama N, Lin T, Lipkowitz S, Park M. A conserved DpYR motif in the juxtamembrane domain of the Met receptor family forms an atypical c-Cbl/Cbl-b tyrosine kinase binding domain binding site required for suppression of oncogenic activation. J Biol Chem 2004; 279: 29565-29571.

28. Janicke RU, Sprengart ML, Wati MR, Porter AG. Caspase-3 is required for DNA fragmentation and morphological changes associated with apoptosis. J Biol Chem 1998; 273: $9357-9360$
29. Chiara F, Bishayee $\mathrm{S}$, Heldin $\mathrm{CH}$, Demoulin JB. Autoinhibition of the platelet-derived growth factor beta-receptor tyrosine kinase by its C-terminal tail. J Biol Chem 2004; 279: 19732-19738.

30. Niu XL, Peters KG, Kontos CD. Deletion of the carboxyl terminus of Tie2 enhances kinase activity, signaling, and function. Evidence for an autoinhibitory mechanism. J Biol Chem 2002; 277: 31768-31773.

31. Bardelli A, Longati P, Williams TA, Benvenuti S, Comoglio PM. A peptide representing the carboxyl-terminal tail of the met receptor inhibits kinase activity and invasive growth. J Biol Chem 1999; 274: 29274-29281.

32. Fischer U, Janicke RU, Schulze-Osthoff K. Many cuts to ruin: a comprehensive update of caspase substrates. Cell Death Differ 2003; 10: 76-100.

33. Yang JY, Widmann C. Antiapoptotic signaling generated by caspase-induced cleavage of RasGAP. Mol Cell Biol 2001; 21: 5346-5358.

34. Yang JY, Michod D, Walicki J, Murphy BM, Kasibhatla S, Martin SJ et al. Partial cleavage of RasGAP by caspases is required for cell survival in mild stress conditions. Mol Cell Biol 2004; 24: 10425-10436.

35. Yang JY, Michod D, Walicki J, Widmann C. Surviving the kiss of death. Biochem Pharmacol 2004; 68: 1027-1031.

36. Paumelle R, Tulasne D, Kherrouche Z, Plaza S, Leroy C, Reveneau S et al. Hepatocyte growth factor/scatter factor activates the ETS1 transcription factor by a RAS-RAF-MEKERK signaling pathway. Oncogene 2002; 21: 2309-2319.

37. Stennicke HR, Salvesen GS. Caspases: preparation and characterization. Methods 1999; 17: $313-319$

Supplementary Information accompanies the paper on Cell Death and Differentiation website (http://www.nature.com/cdd) 